\title{
A Rare Case of Castleman's Disease of Plasma Cell Type Complicated with Membranoproliferative Glomerulonephritis
}

\author{
Mehtap E. UYAR ${ }^{1}$, Emre TUTAL ${ }^{1}$, Zeynep BAL ${ }^{1}$, Eylem AKAR ${ }^{2}$, Sema KARAKUS ${ }^{3}$, Siren SEZER ${ }^{1}$ \\ ${ }^{1}$ Baskent University Faculty of Medicine, Department of Nephrology \\ ${ }^{2}$ Baskent University Faculty of Medicine, Department of Pathology \\ ${ }^{3}$ Baskent University Faculty of Medicine, Department of Hematology, Ankara, TURKEY
}

\section{To Editor,}

Castleman's disease (CD) is an uncommon atypical lymphoproliferative disorder with different histological and clinical forms. Patients with the plasma cell type frequently present with systemic symptoms; including fever, weight loss, hemolytic anemia, hypoalbuminemia, hypergammaglobulinemia and increased acute-phase proteins. ${ }^{1}$ Renal manifestations like proteinuria or hematuria are common in Castleman's disease (CD); ${ }^{2,3}$ however, renal complications including minimal change disease, mesangial proliferative glomerulonephritis, membranous glomerulonephritis and nephrotic syndrome also rarely associates with CD. ${ }^{3,4}$ We herein report a patient with fever, weight loss and increase in inflammatory proteins, anemia and declined renal function that was diagnosed as multicentric type $\mathrm{CD}$ associated with membranoproliferative glomerulonephritis.

A 38-year-old male patient was hospitalized because of a 2-month history of fever, cough, weight loss, anorexia and axillary and inguinal lymph node swelling. The patient's history was not relevant, and he reported no marked surgical history or family history of cancer or any significant systemic disease. Physical examination revealed hepatome- galy and the presence of multiple axillary and inguinal lymphadenopathies. Urinalysis showed proteinuria of $1350 \mathrm{mg} / 24 \mathrm{hr}$ and hyaline casts were identified by sediment analysis. Hematological findings were as follows; hemoglobin $12.2 \mathrm{~g} / \mathrm{dl}$, thrombocytes $142 \times 10^{3} / \mathrm{mm}^{3}$, creatinine $1.5 \mathrm{mg} / \mathrm{dl}$. C-reactive protein $28 \mathrm{mg} / \mathrm{dl}$, erythrocyte sedimentation rate was $95 \mathrm{~mm} / \mathrm{h}$, serum total protein 4.1 $\mathrm{g} / \mathrm{dl}$, serum albumin level $1.5 \mathrm{~g} / \mathrm{dl}$. There was remarkable hypergammaglobulinaemia (immunoglobulin (Ig) G 5439 mg/dl, IgA 782 mg/dl, IgM 181 $\mathrm{mg} / \mathrm{dl}$ ). All CH50 and components of complement, antinuclear antibodies, cryoglobulin and light chains were negative or in normal ranges. Perinuclear anti-neutrophil cytoplasmic antibody and cytoplasmic anti-neutrophil cytoplasmic antibody tests revealed negative results. A bone marrow aspiration was performed in which mild megakaryocytes hyperplasia with normoblastic and micronormoblastic maturation was identified. An abdominal ultrasound revealed hepatomegaly and minimal abdominal fluid. 


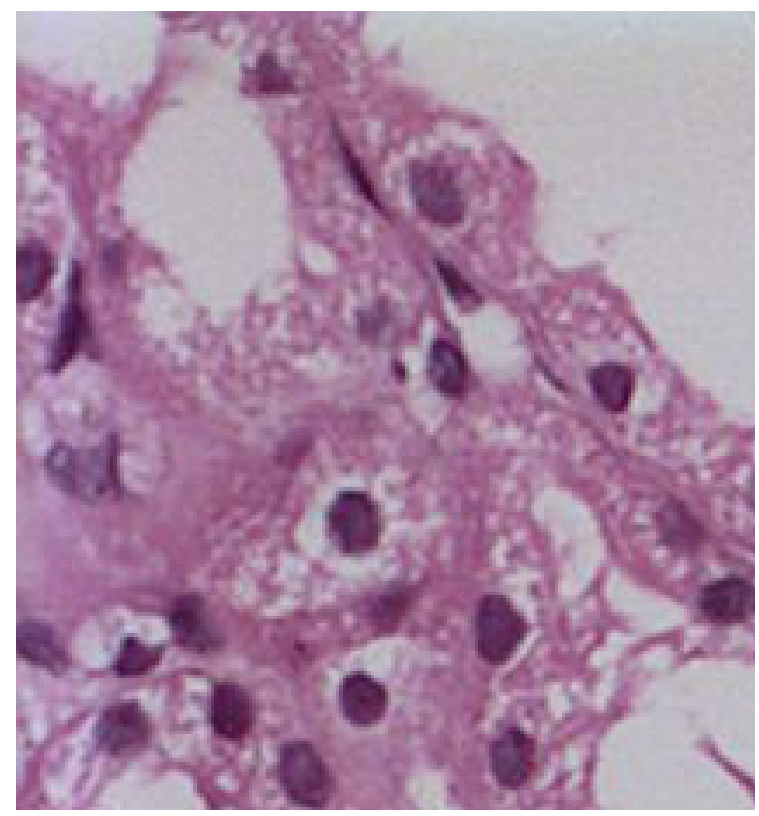

Figure 1. Light microscopy of renal biopsy specimen shows basal membrane thickening, marked mesangial proliferation, interstitial lymphocyte infiltration capillary wall thickening [hematoxylin and eosin (H\&E) stain] (200.).

Sulperazon $2 \times 2 \mathrm{~g}$ IV was administered empirically as the patient had cough, fever and increased acutephase proteins but there was no clinical or laboratory response to parenteral antibiotherapy. During hospitalization the patient's renal function declined, oliguria developed and serum creatinine level was increased to $5.5 \mathrm{mg} / \mathrm{dl}$ in 8 weeks. The patient underwent hemodialysis for three sessions and a renal biopsy was performed in which basal membrane thickening, marked mesangial hyperplasia, interstitial lymphocyte infiltration with the diagnosis of membranoproliferative glomerulonephritis (MPGN) was identified (Figure 1).

Thoracic computed tomography demonstrated paratracheal, precarinal and subcarinal lymphadenopathies, an anterior mediastinal mass of $4 \times 4 \times 2 \mathrm{~cm}$ and pleural effusion. Multiple submandibulary and supraclaviculary lymph nodes were identified by a cervical superficial ultrasound. One submandibulary and one supraclaviculary lymp nodes were excised and a needle aspiration biopsy was performed from the mediastinal lymph node. The excisional lymph node biopsy showed hyperplastic germinal centers, sheets of plasma cells in the interfollicular region, blood vessel proliferation, and persistent sinuses; and plasma cell type $\mathrm{CD}$, was diagnosed.

In conjunction with the patient's clinical findings, a diagnosis of multicentric Castleman's disease was made. The patient was treated with CHOP chemotherapy; $1500 \mathrm{mg}$ cyclophosphamide, $100 \mathrm{mg}$ adriamycin, $2 \mathrm{mg}$ vincristine, and $100 \mathrm{mg}$ prednisolone. The renal function and the constitutional symptoms significantly improved after the first chemotherapy session, serum creatinine level decreased to $0,66 \mathrm{mg} / \mathrm{dl}$. Complete remission was achieved after 8 chemotherapy sessions. The patient recovered without evidence of recurrence, and the follow-up examinations revealed no abnormality.

$\mathrm{CD}$ is a rare clinicopathologic entity among atypical lymphoproliferative disorders; and the plasma cell and mixed types are often associated with 'multicentric Castleman's disease' (MCD), which shows lymphadenopathy, hepatosplenomegaly and various systemic manifestations, such as fever, anemia, hypergammaglobulinemia, hypoalbuminemia, and an increase in acute phase proteins. ${ }^{2}$

Although renal alterations like proteinuria are common in patients with MCD, there are a few reports describing MPGN or MPGN-like glomerulopathy associated with Castleman's disease. ${ }^{5,6}$ Chan et al described a patient who showed MPGN with subendothelial electrondense deposits (5). Conversely, Seida et al reported the occurrence of MPGNlike glomerular lesions without any immunocomplex depositions. ${ }^{6}$ In this report we describe a patient with increase in inflammatory proteins, anemia and declined renal function that diagnosed as multicentric CD associated with MPGN. Our patient had renal involvement in the form of proteinuria and marked glomerular lesions, resulting in the development of acute renal failure. The renal biopsy revealed basal membrane thickening, marked mesangial hyperplasia, interstitial lymphocyte infiltration with the diagnosis of membranoproliferative glomerulonephritis (MPGN) was identified (Figure 1). Patients with multicentric CD do not benefit from surgical treatment and should be given steroid treatment, with or without chemotherapy. ${ }^{2}$ The use of prednisone or other steroids will frequently and promptly improve symptoms. ${ }^{2}$ In some serious cases, patients can take combination of cyclophosphamide, vincristine and prednisone chemotherapy. These have been used as single agents, together with steroids, or in combination eg, cyclophosphamide, doxorubicin, vincristine, and prednisolone $[\mathrm{CHOP}]$ as in our patient.

Our patient responded to treatment with $\mathrm{CHOP}$ regimen. The 8-month follow-up after diagnosis and 
treatment documented an excellent response to the chemotherapy regimen and no evidence of active disease. He remains under active surveillance because he is considered to be at high risk for the development of secondary malignancy.

In summary, we herein reported a rare case of the plasma cell type of MCD with membranoproliferative glomerulonephritis. Clinicians should kept in mind Castleman's disease in the differentional diagnosis of MPGN in patients with constitutional symptoms. Further accumulation of clinical studies including case reports are necessary to confirm the precise effects of Castleman's disease on renal functions.

\section{REFERENCES}

1. Dogan Al, Ayyildiz O, Yakut M, Celik M. Multicentric plasma cell type Castleman's Disease: a case report. UHOD 13: 157-159, 2003.

2. Bowne WB, Lewis JJ, Filippa DA, et al. The management of unicentric and multicentric Castleman's disease: A report of 16 cases and a review of the literature. Cancer 85: 706-717, 1999.

3. Sugimoto T, Ito J, Takeda N, et al. A Case of Castleman's Disease Complicated With Nephrotic Syndrome Due to Glomerulopathy Mimicking Membranoproliferative Glomerulonephritis. Am J Med Sci 335: 495-498, 2008.

4. Uthup S, Balachandran KK, Ammal AV, et al. Renal Involvement in Multicentric Castleman Disease With Glomeruloid Hemangioma of Skin and Plasmacytoma. Am J Kidney Dis 48: E17-E24, 2006.
5. Chan TM, Cheng IK, Wong KL, Chan KW. Resolution of membranoproliferative glomerulonephritis complicating angiofollicular lymph node hyperplasia (Castleman's disease). Nephron 65: 628-632, 1993.

6. Seida A, Wada J, Morita Y, et al. Multicentric Castleman's disease associated with glomerular microangiopathy and MPGN-like lesion: Does vascular endothelial cell-derived growth factor play causative or protective roles in renal injury? Am J Kidney Dis 43: E3-E9, 2004.

\section{Correspondence}

Dr. Mehtap Erkmen UYAR

Aşağı Eğlence Mahallesi

Meșeli Sokak No:15/19

06010 Etlik, ANKARA / TURKEY

Tel: (+90.312) 3257468

Fax: (+90.312) 2130034

e-mail: mehtap94@yahoo.com 